\title{
Performance Prediction and Experimental Analysis of a Solar Liquid Desiccant Air Conditioner
}

\author{
S. Alizadeh ${ }^{1, *}$, H.R. Haghgou ${ }^{1}$ \\ ${ }^{1}$ Department of Energy, Materials \& Energy Research Centre, P. O. Box 14155-4777, Tehran, Iran \\ *Corresponding author. Tel: +98 261620 4131, Fax: +98261 6201888,E-mail: shahab_alizadeh@hotmail.com
}

\begin{abstract}
In a liquid desiccant air conditioner developed at Materials \& Energy Research Centre (MERC), dehumidification of the outside air is achieved through a packed-bed heat and mass exchanger, using lithium chloride solution as the desiccant. The dry air thus obtained is evaporative cooled inside a cooling pad and directed into the conditioned space. The dilute solution from the dehumidification process is concentrated in a scavenger air regenerator using hot water from flat plate solar collectors. Carryover of the desiccant particles has been avoided by using eliminators, such as demister or filter.
\end{abstract}

In this paper the experimental results obtained from testing the prototype of the liquid desiccant absorber unit in a simulated Persian Gulf summer has been presented and compared with a previously developed model for the packed-bed. The comparison reveals that good agreement exists between the experiments and model predictions. The inaccuracies are well within the measuring errors of the temperature, humidity and the air and solution flow rates. The above tests further reveal that the unit would have a satisfactory performance in controlling the air temperature and humidity if installed on a commercial site of about $200 \mathrm{~m}^{2}$ area in a hot and humid climate.

A commercialization study was performed for the solar operated liquid desiccant air conditioner (LDAC) and compared with the conventional vapour compression system. The study reveals that the operating cost of an LDAC is significantly lower than its conventional counterpart. The costs would further reduce if a storage system was used to store the concentrated solution of liquid desiccant. A simple payback of five years was determined for the solar components of the liquid desiccant system in this study.

Keywords: Liquid desiccant, Dehumidification, Packed-bed, Solar regeneration.

\section{Introduction}

Much work has so far been conducted in the area of air dehumidification using liquid desiccant and a cross-flow or a packed-bed type heat and mass exchanger, as the dehumidifier [1]. The use of the solar liquid desiccant air dehumidification / cooling system appears to be promising in hot and humid locations of Iran, such as the Persian Gulf region, due to high availability of solar energy. Figure 1 shows a schematic diagram of the solar air conditioner.

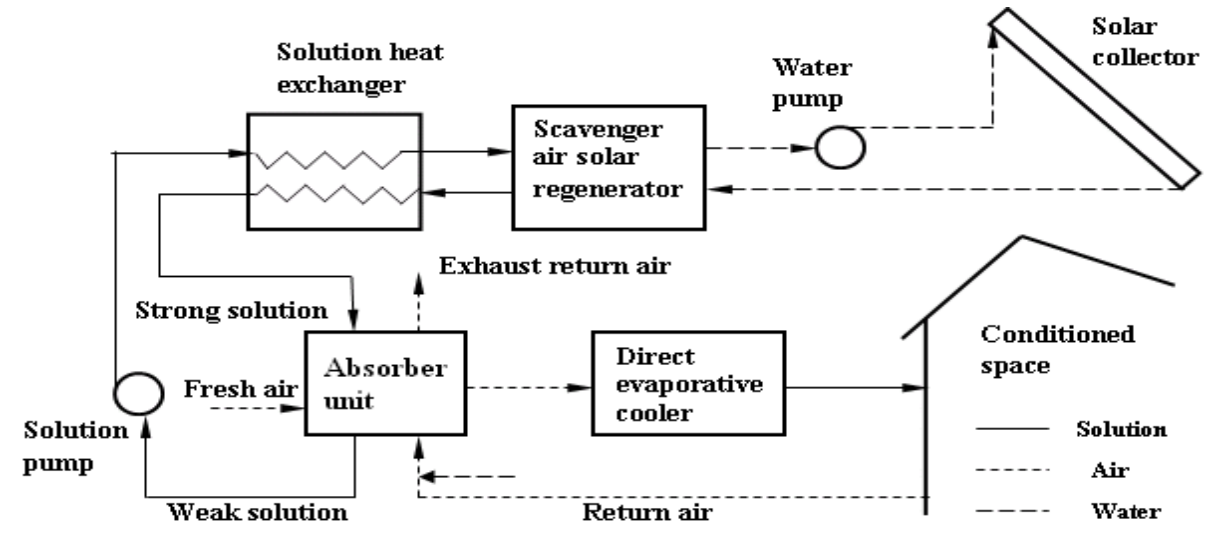

Figure 1. schematic diagram of a liquid desiccant solar air conditioner 
Outside air is dehumidified in the absorber unit using a strong solution of lithium chloride and cooled within a direct evaporative cooler before it is introduced into the conditioned space. The dilute solution thus obtained is concentrated in a scavenger air solar regenerator using hot water from flat plate solar collectors. A solution heat exchanger, as indicated in the figure, is used for heat recovery between the strong and weak solutions. Return air from conditioned space has also been used to take some heat out of the outside air as shown in Figure 1.

Considerable laboratory experiments, computational analysis and design work has been carried out on a liquid desiccant system at the Sustainable Energy Centre of the University of South Australia [2-6], and the Queensland University of Technology [7, 8]. These involved modelling and experimental work on both cross flow and packed-bed dehumidifier as the absorber unit as well as the solar regenerator [9]. In the packed-bed system used in this study, different packing materials are considered, which include the polymer type usually used in cooling tower applications and the counter flow type with a layer of wick applied to the heat exchanger surfaces to reduce the carry over of the desiccant particles into the conditioned space, as well as to increase the dehumidification efficiency of the air conditioning unit.

In a solar liquid desiccant system the weak desiccant can be concentrated, stored and used at a later time; therefore, energy is stored as concentrated solution in the system rather than thermal. The system provides the options of using the solar LDAC either as a packaged roof top air conditioner for domestic or commercial use or as an air handler unit in commercial applications such as conditioning large volumes of ventilation air. The LDAC could also be used for space heating in winter due to the property of desiccants to provide heat when wetted and, thereby, indirectly heat the supply air.

\section{Testing the conditioner prototype}

In the experimental tests carried out on the developed LDAC, dehumidification and cooling are both achieved within the absorber unit by using liquid desiccant and the cool air from the conditioned space, respectively. A photograph of the absorber unit showing the system main components is demonstrated in Figure 2.

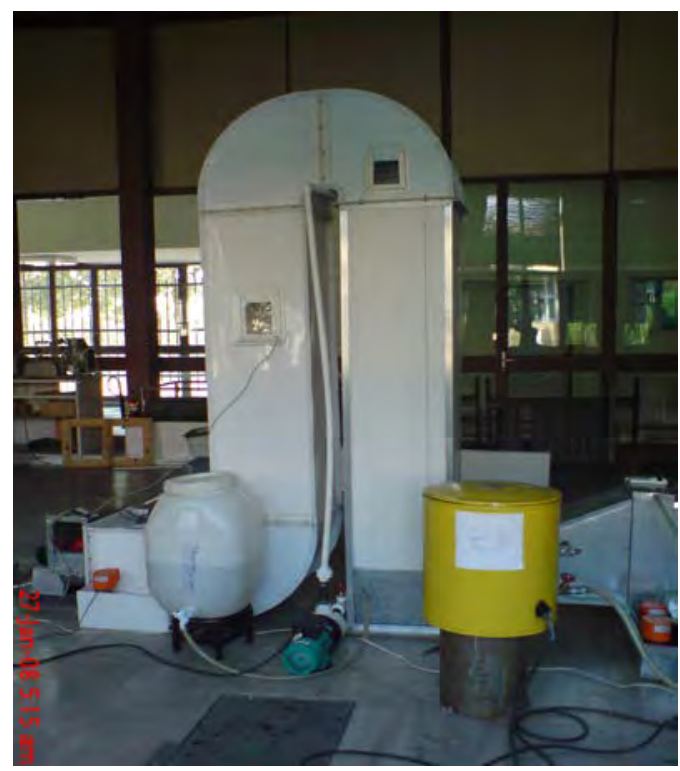

Figure 2. The LDAC packed-bed dehumidification unit as viewed from the MERC Energy Laboratory. 
This $20 \mathrm{~kW}$ unit has an overall dimensions of approximately $1.3 \times 1.5 \times 1.8 \mathrm{~m}$. The conditioner casing is made from an insulating material to protect the system from heat transfer with the environment. The packing material is incorporated vertically inside the dehumidification tower with the weak solution container at the bottom. The conditioner prototype was optimized for the air and solution flow rates, further reducing electrical power consumed by the unit.

Preliminary tests have been carried out on the system with water to ensure a smooth operation of the unit. These involved running the air conditioner at variable fan speeds by reducing the applied voltage from 220 to $110 \mathrm{~V}$. The air velocity on the supply and exhaust sides of the conditioner and on a face area of approximately $0.15 \mathrm{~m}^{2}$ was measured. The power consumed by the fan during the system operation was also measured and recorded.

Two sets of experiments were carried out with liquid desiccant. In the first set of the experiments, the absorber unit was tested with desiccant only sprayed into the outside air, while the direct evaporative cooler was inactivated. The experiments were aimed to investigate the air temperature rise due to condensation of the air moisture content, and reduction in the air relative humidity. The process of dehumidification / cooling of the outside air for these two experiments are shown on the psychrometric chart in Figure 3. The dashed line on this figure represents the test with desiccant only.

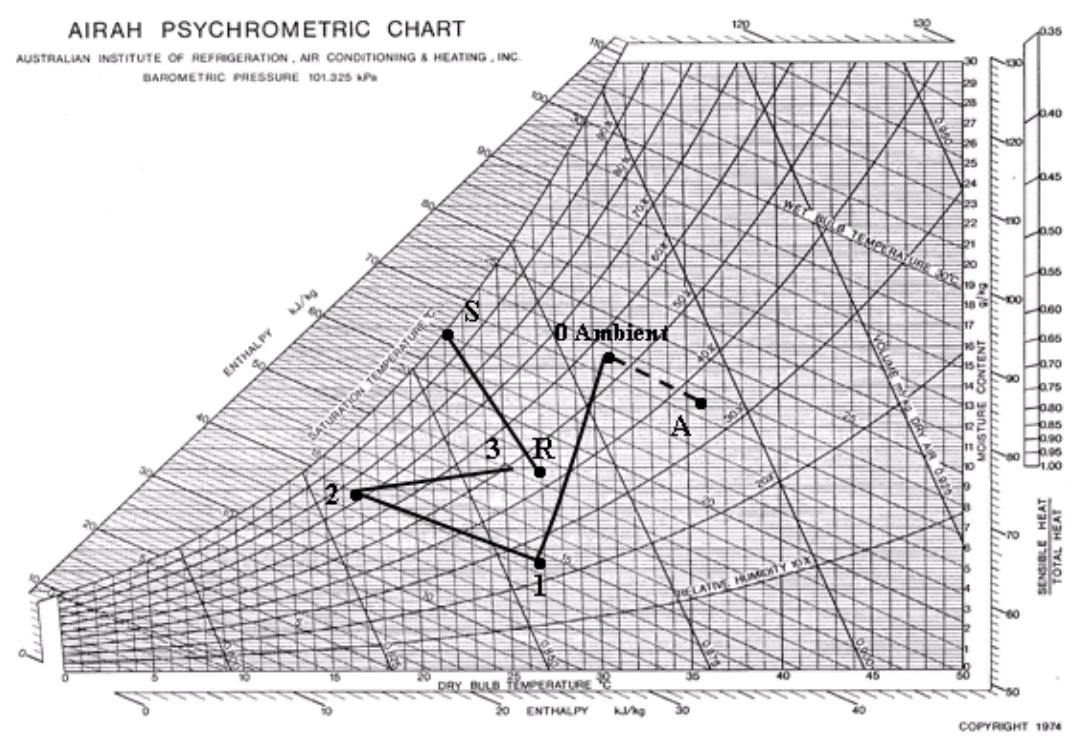

Figure 3. Psychrometric paths for the tests with: (a) desiccant only (dashed line); and (b) desiccant followed by evaporating cooling of the air. (Supply air: 0-1-2-3; Return air: R-S)

In the second set, the system was operated with the evaporative cooler activated, while lithium chloride solution was sprayed into the outside air. The test was to investigate the effect of dehumidification and direct evaporative cooling on the supply air. The process of dehumidification / cooling of the outside air for the above two experiments are shown on the psychrometric chart in Figure 3. The dashed line on this figure represents the test with desiccant only.

Following each set of experiments with liquid desiccant, the concentration of the dilute solution was measured, using a conductivity meter. A plot of conductivity-concentration as 
indicated in Figure 4 was then produced for diluted samples and for several conductivity measurements. The plot was used to determine the subsequent values of concentration for new desiccant solutions, using a correction factor to be accounted for higher concentration values. The weak solution obtained from the dehumidification process in the above experiments was regenerated in a scavenger air solar regenerator. This will be described in section 4.

In Figure 5, the effect of air flow rate on the air temperature and relative humidity of the outside air has been studied. The air temperature and relative humidity on this figure are denoted by $\mathrm{T}_{\mathrm{bp}}$ and $\mathrm{H}_{\mathrm{bp}}$, respectively, which are the air conditions before entering the packedbed column. As seen from the figure a substantial reduction in the air relative humidity is achieved after it passes through the packed-bed column, which is due to the spray of the desiccant solution over the packing material. In Figure 5, values of the air temperature and relative humidity, following the dehumidification process, are denoted as $\mathrm{T}_{\mathrm{ap}}$ and $\mathrm{H}_{\mathrm{ap}}$, respectively.

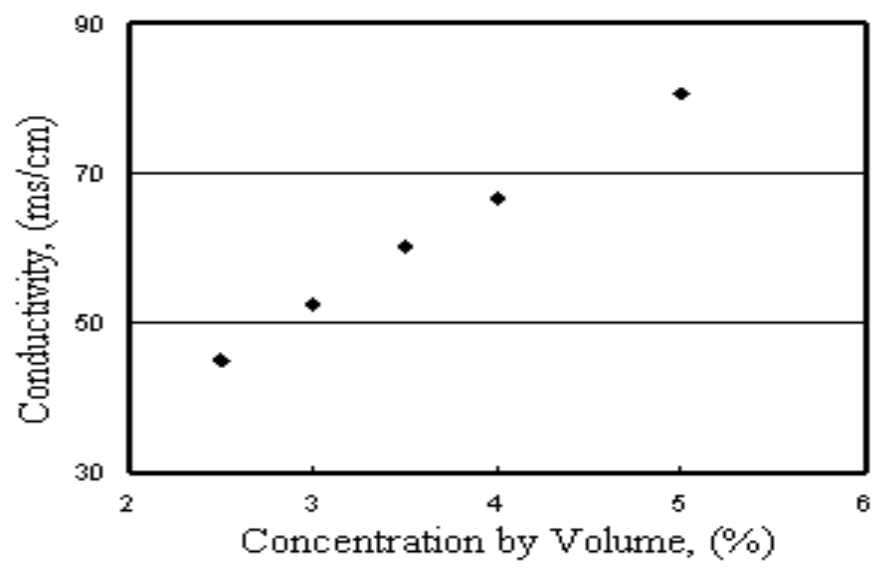

Figure 4. Conductivity-concentration chart for the lithium chloride solution.

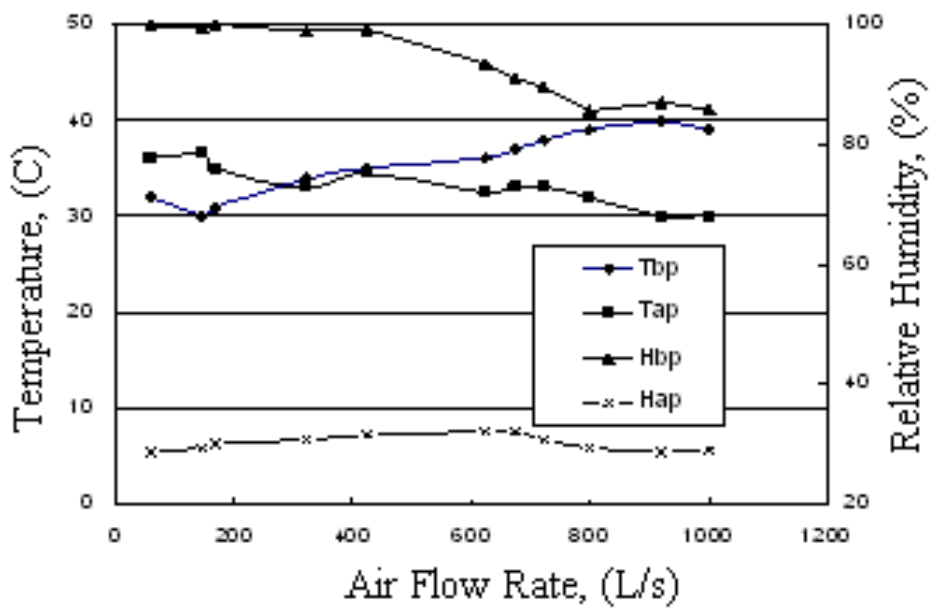

Figure 5. The effect of air flow rate on dehumidification process of the outside air.

In Figure 6 the experimental values of the temperature and humidity after the packing are compared with the predictions obtained from a developed model for the packed-bed. As can be seen from the figure there is good agreement between the data obtained from theory and experiment. 


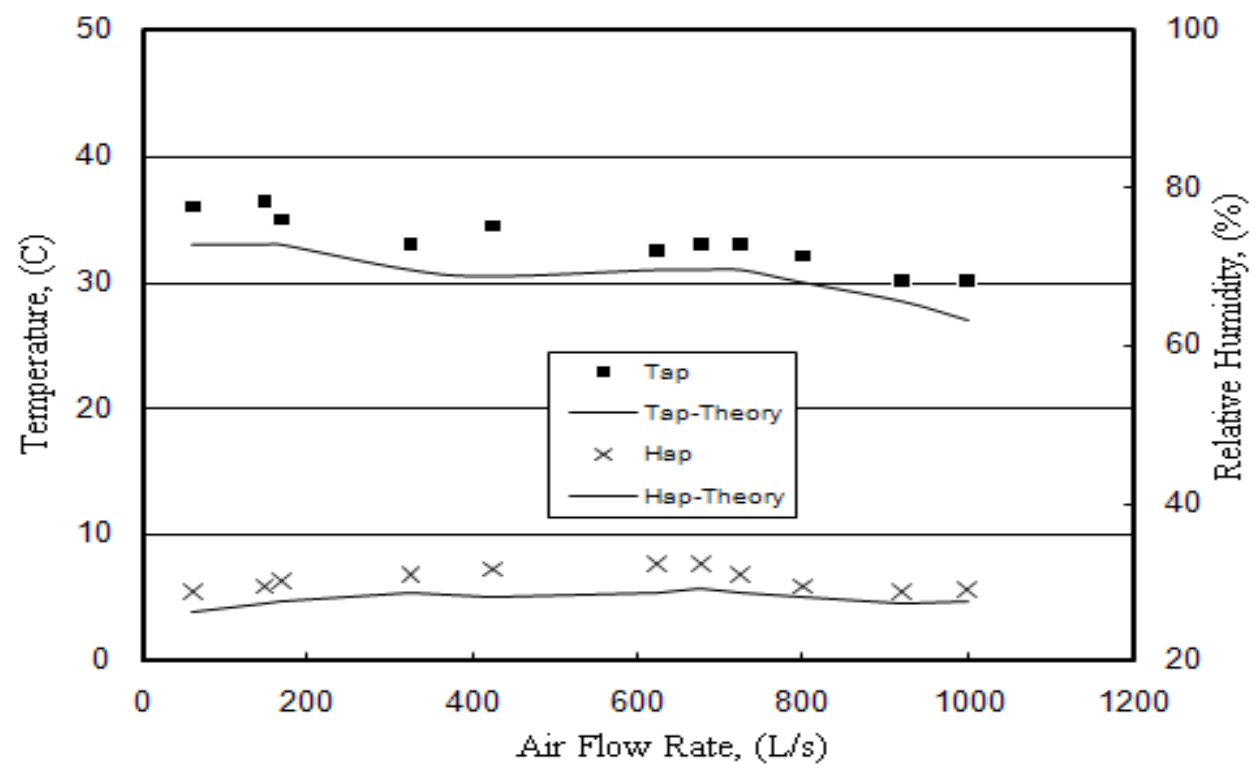

Figure 6. Comparison between the results obtained from the model and experiment.

\section{Discussion of the test results}

In the tests with desiccant only, the air dehumidification by liquid desiccant is an adiabatic (constant enthalpy) process; therefore, no heat is added or removed from the air during the process. However, according to Figure 3, for an adiabatic dehumidification the air dry bulb temperature increases as the relative humidity reduces. This is due to the heat generated in the process as a result of water vapour condensation in the air. The air wet bulb temperature as seen in Figure 3, remains constant.

The results from the tests with evaporative cooler and desiccant prove a satisfactory performance of the unit in a tightly control of the air temperature and humidity if installed on a commercial site of approximately $200 \mathrm{~m}^{2}$ area in a hot and humid climate. This will maintain the building air conditions within the comfort zone (dry bulb temperature of about $25{ }^{\circ} \mathrm{C}$ and $50 \%$ relative humidity). The results of the tests further reveal that there are optimum values of air and solution flow rates, where the conditioner performance is enhanced.

To quantify the confidence level of the experimental data, the results of an uncertainty analysis are presented in Table 1 for the experimental values obtained from testing the conditioner prototype. In this analysis, the fixed errors are assumed to be calculated and accounted for via calibration against known standards. Hence, the remaining error is solely due to the precision error. The precision errors were determined by statistical means or from data provided by equipment manufacturers or by the best estimate based on experimental observations. Since the prototype testing of the absorber unit was under many uncontrolled environmental conditions, the results are quite acceptable.

The results obtained from the demonstration system in this study have been used in a solar liquid desiccant pilot plant project currently ongoing at MERC. The system was built and installed within the Fluid Mechanics Laboratory at Babol University of Technology, a hot and humid location on the Caspian Sea in the north of Iran. The system, which is also used for heating during the winter, is now being tested and monitored for a full year operation. Similar 
equipment will also be installed and tested on the Persian Gulf region in southern part of the country, where the temperature and humidity are very high during most of the year.

Table 1. Experimental results obtained from the conditioner test and the uncertainty values.

\begin{tabular}{lccc}
\hline $\begin{array}{c}\text { Conditioner performance } \\
\text { parameters }\end{array}$ & $\begin{array}{c}\text { Measured } \\
\text { values }\end{array}$ & $\begin{array}{c}\text { Precision } \\
\text { errors }\end{array}$ & $\begin{array}{c}\text { Uncertainty } \\
\text { values } \\
\%\end{array}$ \\
\hline $\begin{array}{l}\text { Supply and return air flow } \\
\text { rates, L/s }\end{array}$ & 1000 & 100 & 10 \\
\hline supply air temperature ${ }^{\circ} \mathrm{C}$ & 15.2 & 1 & 6.7 \\
\hline $\begin{array}{l}\text { supply air humidity ratio, } \\
\mathrm{kg} / \mathrm{kg}\end{array}$ & 0.0094 & 0.0005 & 5.3 \\
\hline Solution flow rate, L/min & 3 & 0.2 & 6.8 \\
\hline $\begin{array}{l}\text { Exit solution } \\
\text { concentration, }(w t \text { \%) }\end{array}$ & 0.412 & 0.008 & 2 \\
\hline Effectiveness, \% & 82 & 5 & 6.1 \\
\hline Latent cooling, $\mathrm{kW}$ & 16.7 & 0.5 & 3.3 \\
\hline Sensible cooling, $\mathrm{kW}$ & 3.3 & 0.1 & 3.1 \\
\hline electrical energy used, $\mathrm{kW}$ & 3 & 0.1 & 3.3 \\
\hline Total cooling, $\mathrm{kW}$ & 20 & 0.6 & 3 \\
\hline Electrical COP & 7 & 0.2 & 2.8 \\
\hline
\end{tabular}

\section{Performance of the solar regenerator}

The concentration of dilute solution in this study is carried out in a scavenger air regenerator, using hot water from flat plate solar collectors. Both the scavenger air and the weak solution are preheated within the regenerator; however, solution regeneration will be more effective when preheating the air than preheating the solution [9]. It is notable that the lithium chloride desiccant can be concentrated using solar energy or other low grade heat at temperatures as low as $40{ }^{\circ} \mathrm{C}$. The flat plate solar collectors used in this study can produce hot water at about $85^{\circ} \mathrm{C}$ in summer.

In a scavenger air regenerator the weak solution is sprayed over a column of packed-bed (see Figure 7). Polymer pall rings, spheres or other polymer based materials are used as a packedbed to increase the contact area between the solution and the scavenger air, which facilitates the regeneration process. A stream of outside air is passed through the column, using a fan, in a counter current operation to pick up the water evaporated from the solution, and the hot moist air is, subsequently, exhausted from top of the column. A mist eliminator, as shown in Figure 6, is used at the top of the regenerator column to prevent the carryover of the desiccant particles. Gas or electricity could be used as a back up for the regenerator during the peak cooling hours.

Eliminators, such as demister, are used to avoid carryover of desiccant into the environment. Alternative method in preventing the carryover is the use of indirect cooling, in which the supply air does not contact the desiccant [10]. The latter could also be used to produce potable water from the atmospheric air in remote areas when a cross flow plate heat exchanger is used. The water can either be used for human consumption or returned to the conditioner for evaporative cooling of the air. 


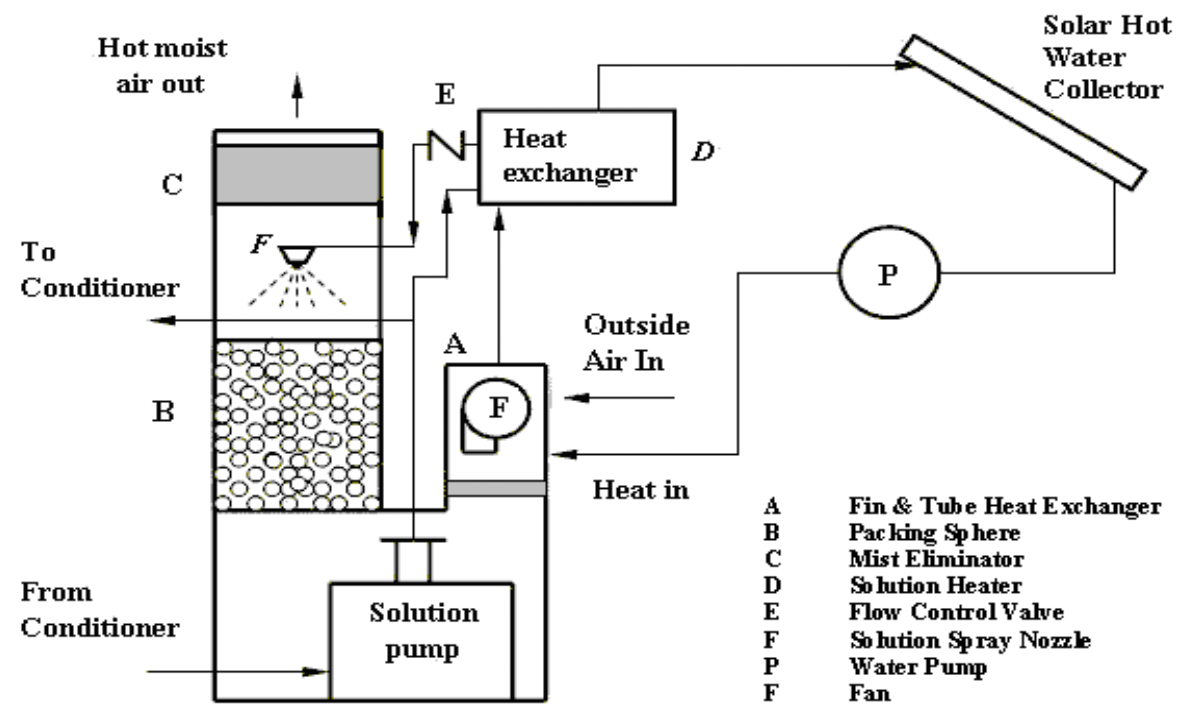

Figure 7. Schematic of the scavenger air solar regenerator.

\section{Commercialization strategy for a solar LDAC}

An LDAC, in which the carryover of the desiccant has been eliminated, creates new opportunities for solar cooling. A commercialization strategy has been proposed in this study for a solar operated LDAC and compared with conventional vapour compression systems. Based on the computer modelling results obtained from the system simulation for a building in the Persian Gulf region, the operating costs of an LDAC is significantly lower than its conventional counterpart. This study further reveals that using the solar operated LDAC with a storage system for the concentrated solution, will result in considerable savings in operating costs when compared with the equivalent gas-fired liquid desiccant system. A simple payback of five years was determined for solar components of the system in this study.

A $30 \mathrm{~kW}$ capacity, packaged roof-top LDAC delivering $1.5 \mathrm{~m}^{3} / \mathrm{s}$ of outside air could be used in domestic applications as well as the commercial. The unit uses a storage system and $100 \mathrm{~m}^{2}$ of flat plate solar collector to dehumidify and cool $500 \mathrm{~m}^{2}$ of a residential building in the Persian Gulf region. Compared with the conventional unit, an annual saving of \$2,500 with a payback of less than 5 years was determined for the solar LDAC in this application.

\section{Conclusion}

In this paper the performance of a solar LDAC developed at MERC, using packed-bed for air dehumidification, and a scavenger air regenerator was studied. It was found that the solar liquid desiccant system is an efficient and cost effective alternative to the conventional air conditioner. Elimination of carryover of the desiccant particles within the absorber unit in this study was performed through the cooling pad of the direct evaporative cooler, which acts as a filter, as well as evaporative cooling of the supply air. Using the indirect cooling technique, the unit could produce potable water from the atmospheric air in remote areas.

Experimental results obtained from prototype testing of the LDAC absorber unit indicates that the unit has a satisfactory performance in controlling the temperature and humidity when installed on a commercial site of about $200 \mathrm{~m}^{2}$ area located on the Persian Gulf region. The tests further reveal that the experiments are in good agreement with a previously developed model for the packed-bed and that the conditioner unit can have an effectiveness of about $82 \%$ when used with liquid desiccant. The maximum electrical energy utilization of the unit, 
which was determined through the above experiments, is $3 \mathrm{~kW}$ with an electrical COP of about 7.

For domestic roof-top applications, it was determined that a $30 \mathrm{~kW}$ capacity LDAC could dehumidify and cool $500 \mathrm{~m}^{2}$ of a residential building on the Persian Gulf with an annual saving of $\$ 2,500$ and a payback of less than 5 years.

\section{References}

[1] Y.J. Dai and H.F. Zhang, Numerical simulation and theoretical analysis of heat and mass transfer in a cross flow liquid desiccant air dehumidifier packed with honeycomb paper, Energy Conversion and Management, 2004, pp. 1343-1356.

[2] W.Y. Saman and S. Alizadeh, Modelling and performance analysis of a cross-flow type plate heat exchanger for dehumidification / cooling, Solar Energy, 2001, pp. 361-372.

[3] W.Y. Saman and S. Alizadeh, Design and Optimization of a Liquid Desiccant Solar Air Conditioner Using Cross Flow Type Plate Heat Exchanger, ISES 2001 Solar World Congress, 2001, Adelaide, Australia.

[4] W.Y. Saman and S. Alizadeh, An experimental study of a cross-flow type plate heat exchanger for dehumidification / cooling. Solar Energy, 2002, pp. 59-71.

[5] S. Alizadeh and W.Y. Saman, Modeling and performance analysis of a forced-flow solar collector / regenerator using liquid desiccant, Solar Energy, 2002, pp. 143-154.

[6] S. Alizadeh and W.Y. Saman, An experimental study of a forced-flow solar collector / regenerator using liquid desiccant, Solar Energy, 2002, pp. 345-362.

[7] S. Alizadeh, and K.Y. Khouzam, “A Study into the Potential of Using Liquid Desiccant Solar Air-Conditioner with Gas Backup in Brisbane - Queensland”, Proceedings of $42^{\text {th }}$ Australian and New Zealand Solar Energy Society, December 1-3, 2004, Perth, W.A.

[8] S. Alizadeh and K. Khouzam, Economical and environmental study of a liquid desiccant solar air conditioner for Queensland, Australia, Proceedings of the ISES Solar World Congress, Orlando, Florida, U.S.A, 6-12 August, 2005.

[9] S. Alizadeh, Development of a dehumidification/ indirect evaporative cooling system using liquid desiccant, $\mathrm{PhD}$ thesis, School of Advanced Manufacturing and Mechanical Engineering, the University of South Australia, Mawson Lakes Campus, S.A., 2002, Australia.

[10] J. L. McNab and P. McGregor, Dual indirect cycle air conditioner uses heat concentrated desiccant and energy recovery in a polymer plate heat exchanger, $21^{\text {st }}$ IIR International Congress of Refrigeration, August 17-22, 2003, Washington DC, USA. 